\title{
COVID-19 and the young heart: what are we missing?
}

\author{
Robert Spencer $^{1}\left(\mathbb{D} \cdot\right.$ Nak Hyun Choi $^{1}\left([) \cdot\right.$ Keriann Potter $^{1} \cdot$ Sanghee Suh $^{1} \cdot$ Michael Fremed $^{1}$
}

Received: 11 June 2020 / Accepted: 25 August 2020 / Published online: 9 September 2020

(c) Children's Hospital, Zhejiang University School of Medicine 2020

As the coronavirus disease 2019 (COVID-19) pandemic continues to evolve, clinicians around the world are reporting a wide spectrum of the virus' clinical manifestations in the pediatric population. The majority of infected children and adolescents appear to present with mild symptoms, such as fever, dry cough, or upper respiratory symptoms [1]. However, because severe cases are rarely reported, data for this population are lacking and the extent of extrapulmonary organ involvement, including the heart, is still being established. The ability to obtain sufficient data is further challenged by the need to minimize risk of exposure to members of the clinical care team, which includes phlebotomists, electrocardiogram technicians, and sonographers.

Myocarditis was first reported in 1749 by a French physician, Jean-Baptiste de Sénac, in his Traité des Maladies du Coeur (Treatise on Disease of the Heart) [2]. Since then, we have learned that viral infections, particularly enteroviruses, represent the most common cause of acute myocarditis in children [3]. We have also learned, sadly, that nearly half of hospitalized pediatric patients with myocarditis require inotropic support and that more than 37\% require mechanical ventilation [4]. While the majority of patients with viral-induced myocarditis survive to hospital discharge, a significant number of those patients go on to develop dilated cardiomyopathy, and many require heart transplants [5].

Are the rates of cardiac injury associated with COVID19 similar to those of other viruses? Are the troponin leaks that have been seen in these patients truly reflective of cardiac injury, especially when there is kidney injury? Should abnormalities in these laboratory values be interpreted the same in children as in adults? The short answer to these questions is that we do not know. In the adult population, Shi and colleagues reported that $20 \%$ of patients with

Robert Spencer

ros9225@nyp.org

1 Division of Pediatric Cardiology, Morgan Stanley Children's Hospital of New York-Presbyterian, Columbia University Medical Center, 3959 Broadway, New York, NY 10032, USA
COVID-19 develop some form of cardiac injury. The same study revealed that having pre-existing cardiovascular disease is associated with more severe progression of the virus and that patients with cardiac injury had a significantly higher likelihood of death compared to those without cardiac injury (51\% versus 5\%, respectively) [6]. But in the absence of more data, it is too early to know the long-term sequelae of cardiac injury in adults, or how these statistics translate to a younger population.

What is needed are studies detailing the cardiac involvement in COVID-19 in children as well as studies comparing the clinical profiles of children with COVID-19 who do and do not have cardiac injury. Perhaps subtle changes on the electrocardiogram or mild elevations in biochemical cardiac markers, such as high-sensitivity troponin and N-terminal pro-B-type natriuretic peptide, have been missed. Characterizing these patients' echocardiographic findings would be helpful. Researchers also should attempt to clarify the pathogenesis of cardiac dysfunction with COVID-19, which has been theorized to involve direct myocardial involvement mediated by angiotensin-converting enzyme-2, although this has yet to be definitively established [7]. Endomyocardial biopsies may help to elucidate the pathogenesis of cardiac injury caused by the virus. Finally, because the number of children with cardiac manifestations of COVID-19 is likely small at any one institution, it may be beneficial to focus attention on collaborative, multicenter studies. These larger studies are best suited to help determine the most successful treatment options, as well as the longitudinal outcomes for these patients.

Aside from the cardiac injury potentially caused by severe acute respiratory syndrome coronavirus 2 (SARS-CoV-2), the exploratory treatments for the virus can pose serious cardiac risks. Hydroxychloroquine and azithromycin, which have been combined to treat many patients of all ages with the virus, are known to prolong the QTc interval and, in rare cases, to cause torsade de pointes [8]. And despite the widespread use of these medications, studies have not shown a significant association with lower in-hospital mortality [9, 10]. At the time of writing of this article, the arrhythmogenic 
potential of other investigational agents, such as remdesivir, is unknown [11]. Patients receiving these novel treatments require close rhythm monitoring, but the optimal monitoring algorithm remains unclear. The safe implementation of these treatments begs several questions: (1) How often should these patients have electrocardiograms? (2) Is telemetry sufficient for monitoring QTc intervals? (3) What is the QTc threshold at which a medication should be held or discontinued?

The multisystem inflammatory syndrome in children (MIS-C), which appears to be associated with COVID19 and has clinical features resembling toxic shock syndrome and atypical Kawasaki disease, also warrants further investigation. Reports of children with this syndrome have increased dramatically in recent months, particularly in Europe and in the United States [12]. Myocardial dysfunction, while usually mild, appears to be present in the majority of patients with this syndrome. A recent study involving 35 patients found that $17 \%$ of patients have coronary artery dilation [13]. While none of those patients was found to have a coronary artery aneurysm, another case series reported one patient with this syndrome who developed a coronary artery aneurysm [14]. Moreover, our center recently published a case series involving 17 previously healthy children with MIS-C, of which 16 had abnormal electrocardiograms, 6 moderate or severe ventricular dysfunction, and 7 prominent or echogenic coronaries. Of note, one of our patients developed a medium-sized aneurysm ( $z$ score, 5.2$)$ of the left anterior descending coronary artery, which resolved on follow-up echocardiogram. All 17 patients were discharged and returned home after a mean of 7 days, with no fatalities [15].

Lastly, information is lacking regarding COVID-19 in patients with complex congenital heart disease (CHD). Adults with complex CHD, particularly those with single ventricle physiology, are predicted to have a higher risk of cardiac sequelae and a worse overall prognosis once infected with COVID-19 [16]. This assumption is made on the basis of their decreased contractile reserve, and further studies are needed to better understand the extent of these patients' risk. Similarly, it would be helpful to know whether patients with complex CHD in the setting of genetic syndromes (e.g., DiGeorge syndrome) or asplenia have particularly poor outcomes due to reduced immunity. Fortunately, the number of patients with complex CHD and COVID-19 remains low at our center, and we continue to advise patients with all forms of CHD to take all possible precautions to minimize potential exposure to the virus.

Despite there being more than 10 million confirmed cases worldwide, the novel coronavirus continues to hold unsolved mysteries [17]. Among these mysteries is how COVID-19 affects children's hearts, how children with cardiac manifestations of the virus can be treated safely, and whether children with complex CHD have worse outcomes. Further epidemiological and multicenter studies are needed to help understand the association between COVID-19 and the heart. Until then, we will continue to face difficult questions and frustrating uncertainty.

Acknowledgements We are deeply grateful to Dr. Julie Glickstein for her support and mentorship.

Author contributions RS conceptualized the manuscript and wrote the original draft. NHC, KP, SS, and MF contributed citations and revised the manuscript.

Funding This study was not funded.

\section{Compliance with ethical standards}

Ethical approval All procedures performed were in accordance with the ethical standards of the institutional research committee and with the 1964 Helsinki Declaration and its later amendments or comparable ethical standards.

Conflict of interest The authors report no conflicts of interest.

\section{References}

1. Castagnoli R, Votto M, Licari A, Brambilla I, Bruno R, Perlini S, et al. Severe acute respiratory syndrome coronavirus 2 (SARS-CoV-2) infection in children and adolescents: a systematic review. JAMA Pediatr. 2020. https://doi.org/10.1001/jamapediatrics.2020.1467.

2. Fung G, Luo H, Qiu Y, Yang D, McManus B. Myocarditis. Circ Res. 2016;118:496-514.

3. Bowles NE, Ni J, Kearney DL, Pauschinger M, Schultheiss $\mathrm{H}-\mathrm{P}, \mathrm{McC}$ arthy $\mathrm{R}$, et al. Detection of viruses in myocardial tissues by polymerase chain reaction. J Am Coll Cardiol. 2003;42:466-72.

4. Canter CE, Simpson KE. Diagnosis and treatment of myocarditis in children in the current era. Circulation. 2014;129:115-28.

5. Singh RK, Canter CE, Shi L, Colan SD, Dodd DA, Everitt MD, et al. Survival without cardiac transplantation among children with dilated cardiomyopathy. J Am Coll Cardiol. 2017;70:2663-73.

6. Shi S, Qin M, Shen B, Cai Y, Liu T, Yang F, et al. Association of cardiac injury with mortality in hospitalized patients with COVID-19 in Wuhan, China. JAMA Cardiol. 2020. https://doi. org/10.1001/jamacardio.2020.0950.

7. Clerkin KJ, Fried JA, Raikhelkar J, Sayer G, Griffin JM, Masoumi A, et al. Coronavirus disease 2019 (COVID-19) and cardiovascular disease. Circulation. 2020. https://doi.org/10.1161/CIRCU LATIONAHA.120.046941.

8. Roden DM, Harrington RA, Poppas A, Russo AM. Considerations for drug interactions on QTc in exploratory COVID-19 (Coronavirus Disease 2019) treatment. Circulation. 2020. https://doi. org/10.1161/CIRCULATIONAHA.120.047521.

9. Geleris J, Sun Y, Platt J, Zucker J, Baldwin M, Hripcsak G, et al. Observational study of hydroxychloroquine in hospitalized patients with COVID-19. N Engl J Med. 2020;382:2411-8.

10. Rosenberg ES, Dufort EM, Udo T, Wilberschied LA, Kumar J, Tesoriero J, et al. Association of treatment with hydroxychloroquine 
or azithromycin with in-hospital mortality in patients with COVID19 in New York state. JAMA. 2020;323:2493.

11. Wu C-I, Postema PG, Arbelo E, Behr ER, Bezzina CR, Napolitano C, et al. SARS-CoV-2, COVID-19 and inherited arrhythmia syndromes. Heart Rhythm. 2020. https://doi.org/10.1016/j.hrthm .2020.03.024.

12. Schroeder AR, Wilson KM, Ralston SL. COVID-19 and Kawasaki disease: finding the signal in the noise. Hosp Pediatr. 2020. https ://doi.org/10.1542/hpeds.2020-000356.

13. Belhadjer Z, Méot M, Bajolle F, Khraiche D, Legendre A, Abakka $S$, et al. Acute heart failure in multisystem inflammatory syndrome in children (MIS-C) in the context of global SARS-CoV-2 pandemic. Circulation. 2020.https://doi.org/10.1161/CIRCU LATIONAHA.120.048360.

14. Riphagen S, Gomez X, Gonzalez-Martinez C, Wilkinson N, Theocharis P. Hyperinflammatory shock in children during COVID-19 pandemic. The Lancet. 2020. https://doi.org/10.1016/S0140 -6736(20)31094-1.

15. Cheung EW, Zachariah P, Gorelik M, Boneparth A, Kernie SG, Orange JS, et al. Multisystem inflammatory syndrome related to COVID-19 in previously healthy children and adolescents in New York City. JAMA. 2020. https://doi.org/10.1001/jama.2020.10374.

16. Tan W, Aboulhosn J. The cardiovascular burden of coronavirus disease 2019 (COVID-19) with a focus on congenital heart disease. Int J Cardiol. 2020;309:70-7.

17. Dong E, Du H, Gardner L. JHU. COVID-19 dashboard by the Center for Systems Science and Engineering (CSSE) at Johns Hopkins University (JHU). 2020. https://coronavirus.jhu.edu/map. html. Accessed 30 June 2020.

Publisher's Note Springer Nature remains neutral with regard to jurisdictional claims in published maps and institutional affiliations. 